\title{
Cultivo de Oreochromis niloticus (Linaeus, 1758) em sistema de recirculação de água associado ao fitotratamento
}

Cultivation of Oreochromis niloticus (Linaeus, 1758) in phytotratament associated water recirculation system

Cultivo de Oreochromis niloticus (Linaeus, 1758) en sistema de recirculación de agua asociado al fitotratamiento

\author{
Matheus Della Tonia Marchesi ${ }^{1}$ \\ Débora Cristina Souza ${ }^{2}$ \\ Sonia Barbosa Lima ${ }^{3}$
}

${ }^{1}$ Mestrando em Tecnologias Ambientais pela Universidade Tecnológica Federal do Paraná, Campus Francisco Beltrão. Graduação em Engenharia Ambiental pela Universidade Tecnológica Federal do Paraná, Campus Campo Mourão. E-mail: matheusmarchesi@hotmail.com

${ }^{2}$ Mestrado e doutorado em Ecologia de Ambientes Aquáticos Continentais pela Universidade Estadual de Maringá (UEM). Graduação em Ciências Biológicas pela UEM. Professora da Universidade Tecnológica Federal do Paraná. Departamento de Biodiversidade e Conservação, Campus Campo Mourão, Paraná. E-mail: dcsouza@utfpr.edu.br

${ }^{3}$ Doutorado em Ciências pelo Programa de Pós-Graduação em Química na Universidade Estadual de Maringá. Mestrado em Química e graduação em Licenciatura e Bacharelado em Química, ambos pela Universidade Estadual de Maringá. Professora e Coordenadora de Ambiental, Departamento de Biodiversidade e Conservação, da Universidade Tecnológica Federal do Paraná, Campus Campo Mourão, Paraná E-mail: barbosadelimas@gmail.com 
Resumo: O desafio para o sistema fechado de criação de peixes é garantir a qualidade da água, assim o presente estudo avaliou um sistema de tratamento biológico utilizando macrófitas aquáticas associado a um tanque de cultivo intensivo de Oreochromis niloticus, em sistema fechado. O experimento foi realizado em duas repetições de 105 dias e de 152 dias, e mediu-se o oxigênio dissolvido, a temperatura, o pH, a amônia total, a amônia não ionizada e o nitrito. Todos os parâmetros se mantiveram dentro dos limites ideais de cultivo, no entanto a conversão alimentar aparente foi de $3,23 \mathrm{Kg} / \mathrm{Kg}$ de peixe no primeiro manejo e de 4,48Kg \Kg de peixe no segundo. O baixo ganho de biomassa está relacionado às baixas temperaturas dos dois períodos de cultivo. O tratamento biológico se mostrou eficiente controlando os parâmetros considerados importantes no cultivo de peixes, e indica-se a utilização deste sistema de baixo custo de operação.

Palavras-chave: biotratamento; amônia; conversão alimentar.

Abstract: The challenge for the closed fish breeding system is to guarantee the quality of the water, so the present study evaluated a biological treatment system using aquatic macrophytes associated with an intensive culture tank of Oreochromis niloticus, in a closed system. The experiment was carried out in two replicates of 105 days and 152 days and the dissolved oxygen, temperature, $\mathrm{pH}$, total ammonia, non-ionized ammonia and nitrite were measured. All parameters were kept within ideal growth limits, however the apparent feed conversion was $3.23 \mathrm{Kg} / \mathrm{Kg}$ of fish in the first management and $4.48 \mathrm{Kg} / \mathrm{Kg}$ of fish in the second. The low biomass gain is related to the low temperatures of the two growing periods. The biological treatment was efficient controlling the parameters considered important in the fish culture and indicated the use of this system of low cost of operation.

Keywords: biotreatment; ammonia; feed conversion.

Resumen: El desafío para el sistema cerrado de cría de pescado es garantizar la calidad del agua, así que el presente estudio evaluó un sistema de tratamiento biológico utilizando macrófitas acuáticas asociado a un tanque de cultivo intensivo de Oreochromis niloticus, en sistema cerrado. El experimento fue realizado en dos repeticiones de 105 días y de 152 días y se midió el oxígeno disuelto, la temperatura, el pH, el amoníaco total, el amoníaco no ionizado y el nitrito. Todos los parámetros se mantuvieron dentro de los límites ideales de cultivo, sin embargo, la conversión alimenticia aparente fue de $3,23 \mathrm{Kg} / \mathrm{Kg}$ de pescado en el primer manejo y de 4,48 Kg/Kg de pescado en el segundo. La baja ganancia de biomasa está relacionada con las bajas temperaturas de los dos períodos de cultivo. El tratamiento biológico se mostró eficiente controlando los parámetros considerados importantes en el cultivo de peces e indicó la utilización de este sistema de bajo costo de operación.

Palabras clave: biotratamiento; amoníaco; conversión alimentícia. 


\section{INTRODUÇÃO}

A exploração pesqueira não é um tema alarmante e inclusive fica à parte quando se trata de impactos de desflorestamentos, desertificação e exploração de recursos energéticos que reduzem a biodiversidade. Porém é necessário aumentar a atenção a essa atividade devido à intensa sobrepesca, que, embora se trate de pesca feita de forma correta e legal, é realizada acima do limite em se tratando de uma espécie que tem de se autorrepor na natureza. A pesca descontrolada representa problemas graves, pois significa uma grande ameaça à redução de alimento e à biodiversidade.

Uma forma de reduzir os problemas da sobrepesca é a criação em cativeiro das espécies de interesse comercial. A aquicultura é uma atividade que vem se destacando no agronegócio e que se encontra diante do desafio de moldar-se ao conceito de sustentabilidade. Isto implica agregar novos ideais à racionalidade produtiva, sobretudo incorporar as dimensões sociais, econômicas e ambientais aos sistemas implantados.

No período de 2000 a 2012, a produção aquícola cresceu de 6,3 a $8 \%$ no mundo. A intensificação da aquicultura deve proceder de maneira cautelosa, pois deve-se considerar que os efluentes líquidos gerados têm efetivo potencial de alterar a qualidade dos corpos hídricos. A definição do grau de poluição gerado por cada modelo de cultivo, bem como a eficiência obtida pelas diferentes técnicas de tratamento do efluente gerado pela atividade, é de grande importância para estabelecer normas básicas para o desenvolvimento da atividade.

Sobretudo, é necessário que os métodos de tratamento dos efluentes da atividade aquícola sejam de baixo custo e fácil operação. Seguindo essa premissa, os desenvolvimentos de sistemas fechados mostram-se importantes, pois permitem a produção de peixes e outros animais aquáticos com pequena geração de efluentes líquidos. Comparando-se os sistemas tradicionais de cultivos de peixes em cativeiro com os de recirculação, estes permitem menor consumo de água por quilo de peixe produzido (redução de mais de 90\%), além de ter a vantagem de praticamente anular a emissão de efluentes, reduzindo assim os impactos ambientais, atendendo aos conceitos de uma aquicultura ambientalmente correta. 
O desafio neste sistema é garantir a qualidade da água para a sobrevivência e o bom desenvolvimento das espécies cultivadas. Assim o presente estudo objetivou implantar e avaliar o funcionamento de um tratamento biológico utilizando macrófitas aquáticas flutuantes, associado a um tanque de cultivo intensivo de peixes, em sistema fechado com recirculação de água.

\section{MATERIAIS E MÉTODOS}

O trabalho consistiu na avaliação de um sistema fechado de cultivo de Oreochromis niloticus (Linnaeus, 1758) (tilápia) associado a um filtro biológico com Salvinia auricullata Aublet. e Salvinia biloba Raddi (Salvinaceae), aplicando reuso e fluxo contínuo de água. O experimento foi realizado em duas repetições durante 105 dias, entre agosto e dezembro, e durante 152 dias, entre abril e setembro.

O modelo experimental era composto por duas caixas circulares de polietileno, com capacidade de 500 litros cada uma; a primeira destinada à criação de Oreochromis niloticus e a segunda ao tratamento do efluente gerado pela atividade aquícola através de fitotratamento com as macrófitas aquáticas. A água colocada no sistema tinha por origem poço artesiano e somente foi reposta para manter o nível devido à evaporação. Em dias chuvosos, o nível de água foi mantido estático devido a um orifício próximo à borda superior dos tanques.

\subsection{Tanque de criação}

A densidade de estocagem foi estabelecida com dados de Capacidade de Suporte para Sistemas de cultivo com recirculação de água para produção de Tilápias (20 a $60 \mathrm{~kg} / \mathrm{m}^{3}$ ) (KUBITZA, 2000). Portanto, tanto no primeiro quanto no segundo manejo, foram introduzidos aproximadamente 50 alevinos com peso médio de 5 gramas.

\subsection{Fitotratamento}

O tanque de fitotratamento era composto, além das macrófitas aquáticas, por 8 tijolos de cerâmica de seis furos dispostos no fundo do tanque e $20 \mathrm{~kg}$ de argila expandida $5 \mathrm{~mm}$. Os tijolos e os seixos de argila expandida 
foram utilizados por possuírem extremidade porosa, tornando-se abrigo de bactérias nitrificantes que se proliferam rapidamente na presença de compostos nitrogenados no meio líquido.

\subsection{Recirculação}

Através de uma bomba hidráulica submergível, fez-se o bombeamento constante de água que fluiu do tanque de tratamento para o tanque de criação. A vazão média obtida foi de 132 litros por hora. O fluxo de água constante é muito importante, pois é o responsável pela dissolução de oxigênio no meio (SIPAÚBA-TAVARES; MILLAN; MILSTEIN, 2016).

A água foi bombeada para o tanque de criação a uma altura de 1 metro em relação à superfície líquida. A saída de água se localizava no centro do tanque, favorecendo a limpeza a partir do escoamento (GONTIJO, 2013). A bomba foi posicionada no interior de uma estrutura que assegurou a captação da água a uma distância de aproximadamente 10 centímetros da superfície, evitando a absorção de raízes das macrófitas, bem como partículas densas que se acumulam na parte inferior do tanque, garantindo o bom funcionamento da bomba hidráulica.

\subsection{Sistema adutor}

O sistema adutor foi construído utilizando canos e conexões de PVC de 100 milímetros. O bombeamento da água resultou da diferença entre a altura hidráulica dos tanques, e, por estarem conectados, a água fluiu através do sistema de adução gerando assim um fluxo contínuo de água enquanto a bomba hidráulica estivesse ligada.

A limpeza do sistema ocorria semanalmente, e uma válvula de retenção era utilizada para interromper o fluxo de água.

\subsection{Manejo alimentar}

Os peixes foram alimentados com $5 \%$ da biomassa total do viveiro por dia, dividido em três refeições diárias, exceto em dias com temperaturas abaixo de $19^{\circ} \mathrm{C}$, em que se forneceu $2,5 \%$ da biomassa total do viveiro por dia, uma única vez ao dia (KUBITZA, 2000). Em ambos os períodos, no pri- 
meiro mês foi fornecida ração artesanal farelada contendo $45 \%$ de proteína bruta. A partir do segundo mês, foi fornecida ração comercial paletizada com diâmetro entre 1 e 3 mm, contendo 35\% de proteína bruta.

\subsection{Indicadores de produção}

A partir das pesagens, inicial e final, dos peixes e histórico de alimentação, foram realizados cálculos para definir as características de desempenho: peso médio inicial, peso médio final, ganho de biomassa total, ganho de biomassa individual, ganho de biomassa individual diária e conversão alimentar aparente.

\subsection{Análises dos dados}

Foram medidos na água dos tanques o oxigênio dissolvido, a temperatura, o pH, a amônia total, a amônia não ionizada e o nitrito, no início da manhã e no final da tarde, obtendo a média diária para cada parâmetro duas vezes por semana. Ao todo foram 64 medições de cada parâmetro, no primeiro manejo, e 106 para cada parâmetro, no segundo manejo.

$\mathrm{O}$ pH foi medido com um pHmetro portátil da marca Schott Gerate modelo CG818. Para determinação de Oxigênio dissolvido, utilizou-se um medidor digital portátil de oxigênio dissolvido e termômetro da marca Lutron modelo DO 5519

O nitrito, amônia total e amônia não ionizada foram determinados utilizando metodologia colorimétrica e titulométricas (EATON, 2005). Os dados obtidos foram dispostos em gráficos comparando com os parâmetros ideais (KUBITZA, 2000) para o cultivo da Tilápia (Tabela 1).

Tabela 1 - Parâmetros ideais para o cultivo de Tilápia em sistemas fechados

\begin{tabular}{lc}
\hline Parâmetro & Faixa ideal \\
\hline Temperatura & 27 a $32(\mathrm{o} \mathrm{C})$ \\
pH & 6 a 8.5 \\
Oxigênio Dissolvido & $>3(\mathrm{mg} / \mathrm{L})$ \\
Amônia Total $\left(\mathrm{NH}_{3}\right)$ & $<2.3(\mathrm{mg} / \mathrm{L})$ \\
Amônia não ionizada $\left(\mathrm{NH}_{4}\right)$ & $<0.2(\mathrm{mg} / \mathrm{L})$ \\
Nitrito & $<0.5(\mathrm{mg} / \mathrm{L})$ \\
\hline
\end{tabular}

Fonte: Compilados de Kubitza (2000). 


\section{RESULTADOS E DISCUSSÃO}

A temperatura média obtida no tanque de criação foi de $22,9^{\circ} \mathrm{C}$ no primeiro manejo e, no segundo, de $16,2^{\circ} \mathrm{C}$ (Figura 1). A temperatura da água se manteve muito próxima no interior dos dois tanques (Figura $1 \mathrm{~A}$ e $1 \mathrm{~B}$ ). Muitos autores destacam a relação existente entre o ganho de biomassa dos peixes e a temperatura da água (OSTRENSKY; BOEGER, 1998).

Figura 1 - Dados de variação de temperatura no primeiro manejo (A) e no segundo manejo (B) de Oreochromis niloticus em sistema de recirculação associado a fitotratamento

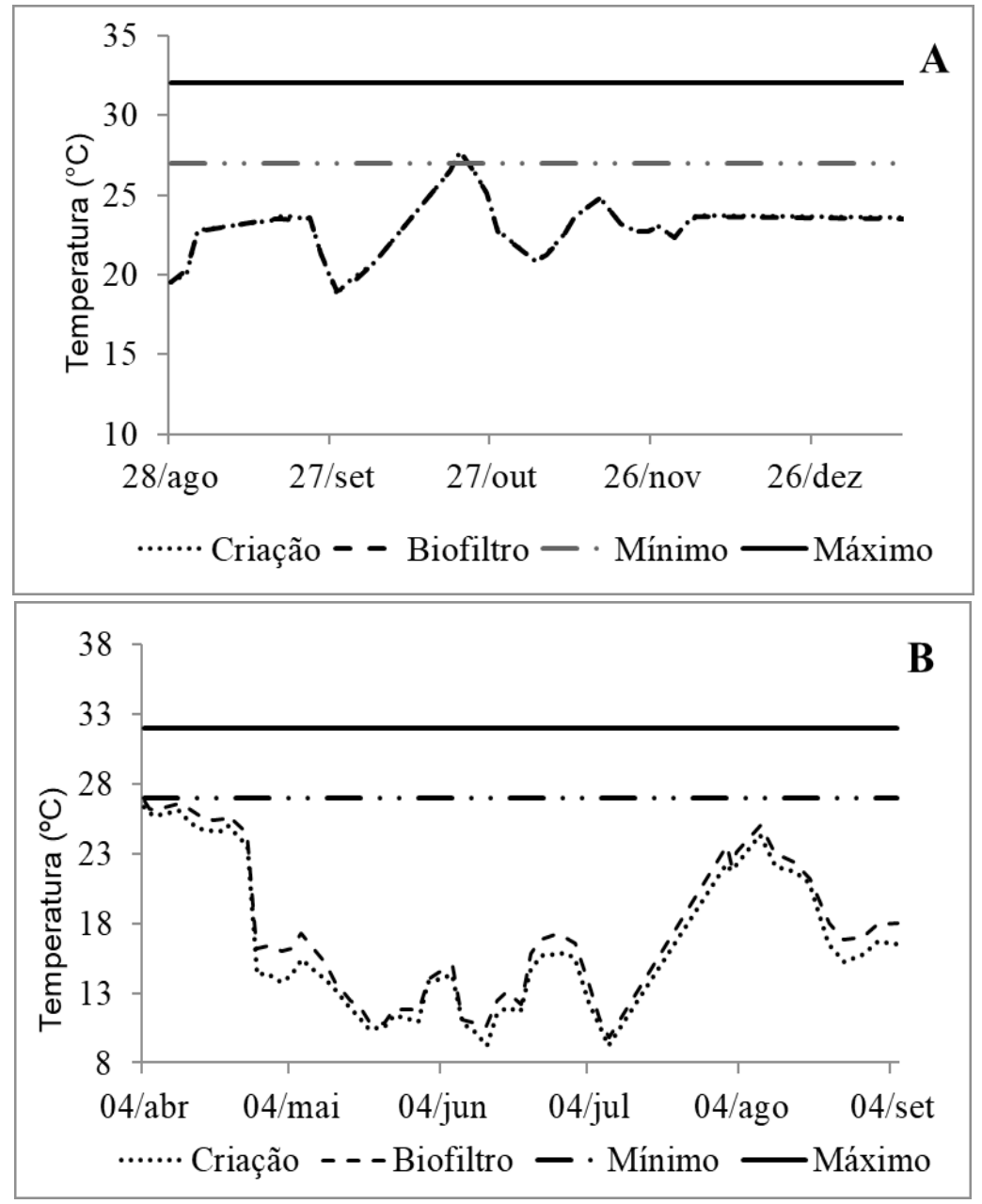

Fonte: Autoria própria. 
O oxigênio dissolvido na água é outro elemento muito importante e apresentou níveis satisfatórios durante todo o experimento, com valores adequados para a atividade aquícola. No primeiro manejo, não ocorreram grandes variações entre o oxigênio dissolvido na água do tanque de criação e o no tanque de tratamento, mantendo-se em média 4,88 mg/L (Figura 2A).

No segundo manejo, os índices de oxigênio dissolvido obtidos se apresentaram mais elevados no tanque de criação, onde a concentração chegou a 8,2 mg/L. E a concentração mínima ficou em 4,0 mg/L na água do biofiltro. As concentrações médias de oxigênio dissolvido nesse segundo período foram de 6,34 mg/L e 4,66 mg/L, obtidas no tanque de criação e biofiltro respectivamente (Figura $2 \mathrm{~B}$ ). A oxigenação da água está diretamente relacionada com o metabolismo dos microrganismos, o aumento de oxigenação no meio permite a maior assimilação de $\mathrm{C}$ pelos microrganismos (CASELLES-OSORIO; GARCIA, 2007). 
Figura 2 - Dados de variação de oxigênio dissolvido no primeiro manejo (A) e no segundo manejo (B) de Oreochromis niloticus em sistema de recirculação associado a fitotratamento
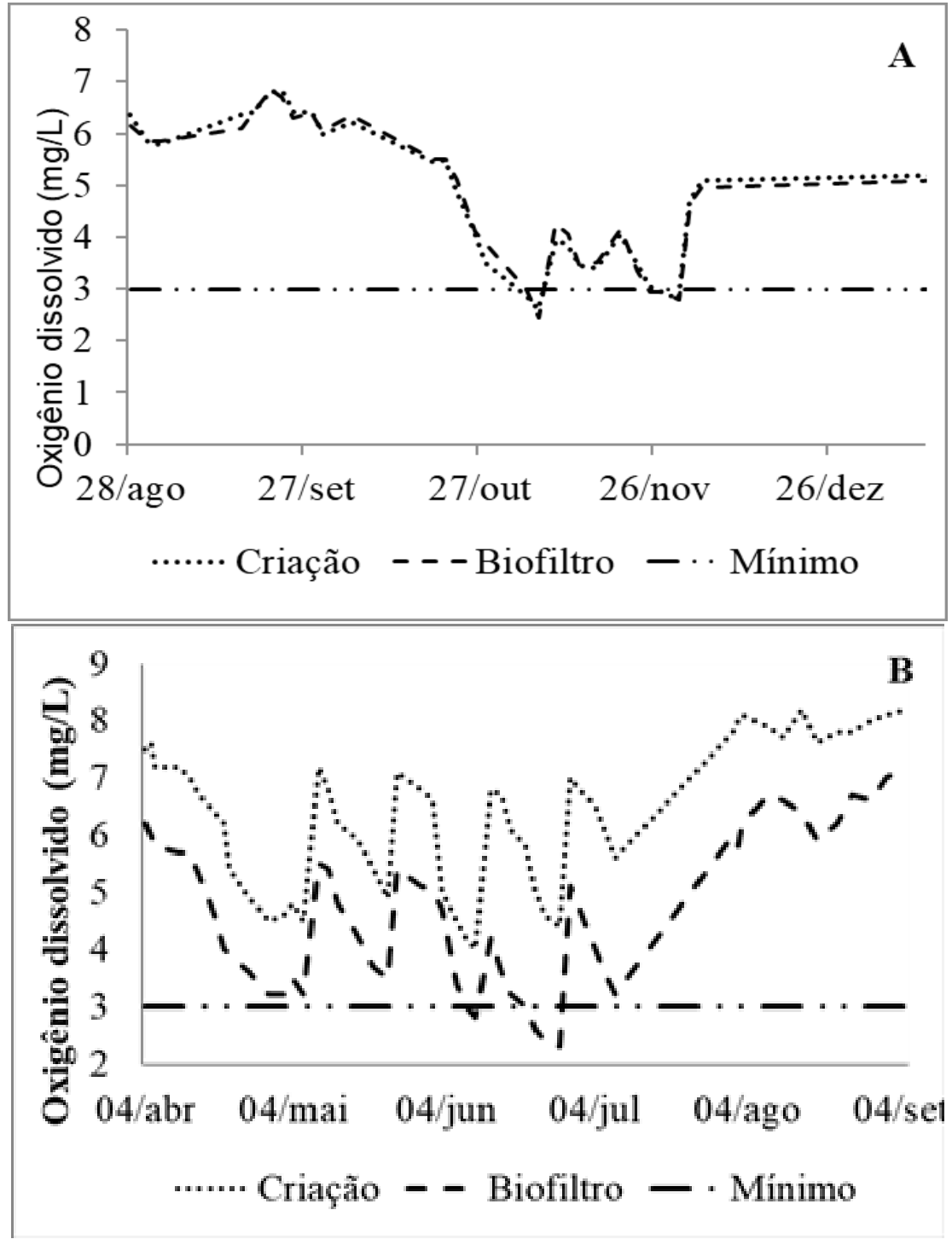

Fonte: Autoria própria.

A variação entre a concentração de oxigênio dissolvido nos dois tanques no segundo manejo se deveu ao ajuste na altura de bombeamento da água, a posição da mangueira foi elevada em 0,7 metros. O segundo 
manejo também apresentou maior oscilação nos níveis de oxigênio, que coincidiram com os dias de limpeza da bomba; sempre após a limpeza, os níveis retornam a valores próximos do dia inicial de criação. A limpeza da bomba hidráulica se fez necessária devido à proliferação de lodo em suas paredes, o que afetou sua eficiência. A vazão de bombeamento sofria significativa alteração após a limpeza passando de 75 litros por hora para 135 litros, promovendo maior velocidade a água e consequentemente maior oxigenação.

Durante os três últimos meses de manejo, a concentração de oxigênio dissolvido da água manteve padrões mais elevados e constantes em relação ao início do manejo. Essas datas coincidem com a incidência e proliferação de caramujos no meio. Os caramujos controlaram o lodo; à medida que se proliferaram, não mais se encontrava lodo nas paredes da bomba hidráulica, garantindo assim a estabilidade da oxigenação.

$\mathrm{O}$ pH manteve-se de básico a levemente ácido nos dois períodos, não atingindo nível prejudicial aos peixes permanecendo na faixa ideal para cultivo da espécie (Figura 3). Manteve-se entre 6,5 a 7,85 (Figura 3A) no primeiro e, no segundo manejo, o maior $\mathrm{pH}$ foi 7,44 em agosto, e o menor foi 6,81 em junho (Figura 3B). O pH influencia diretamente no bem-estar dos peixes, a acidez excessiva na água causa aumento na secreção de muco, irritação e inchaço nas brânquias, podendo resultar no comprometimento do tecido branquial (KUBITZA, 2006). 
Figura 3 - Valores de pH da água no primeiro manejo $(\mathrm{A})$ e no segundo manejo (B) de Oreochromis niloticus em sistema de recirculação associado a fitotratamento.

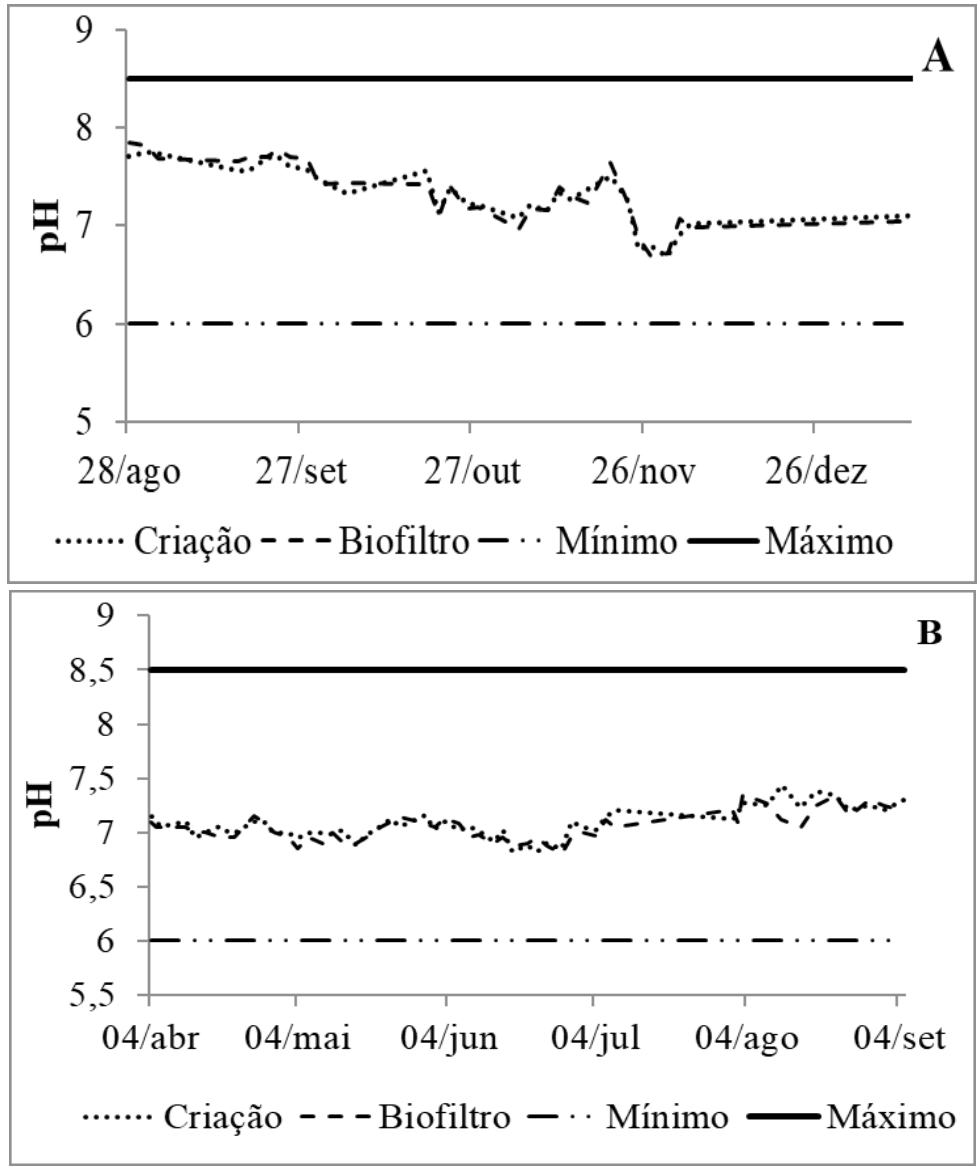

Fonte: Autoria própria.

O metabolismo aquático também está diretamente relacionado ao $\mathrm{pH}$, com alterações na capacidade de decomposição dos microrganismos e alterando os compostos nitrogenados do meio. Para o desenvolvimento bacteriano, o pH deve ficar na faixa de 6,3 a 7,9 (VYMAZAL; KRÖPFELOVÁ, 2009), sendo esta também a faixa que permite a melhor absorção de nutrientes pelas plantas aquáticas (ÓLGUIN; SÁNCHEZ-GALVÁN, 2010).

As concentrações de amônia total refletem o bom metabolismo aquático do sistema, sempre ficando abaixo dos níveis considerados tóxicos aos 
peixes, ficando praticamente nula durante o primeiro manejo (Figura 4A) e com pequenas variações no segundo manejo (Figura 4B).

Figura 4- Concentração média de amônia total no primeiro manejo (A) e no segundo manejo (B) de Oreochromis niloticus em sistema de recirculação associado a fitotratamento.

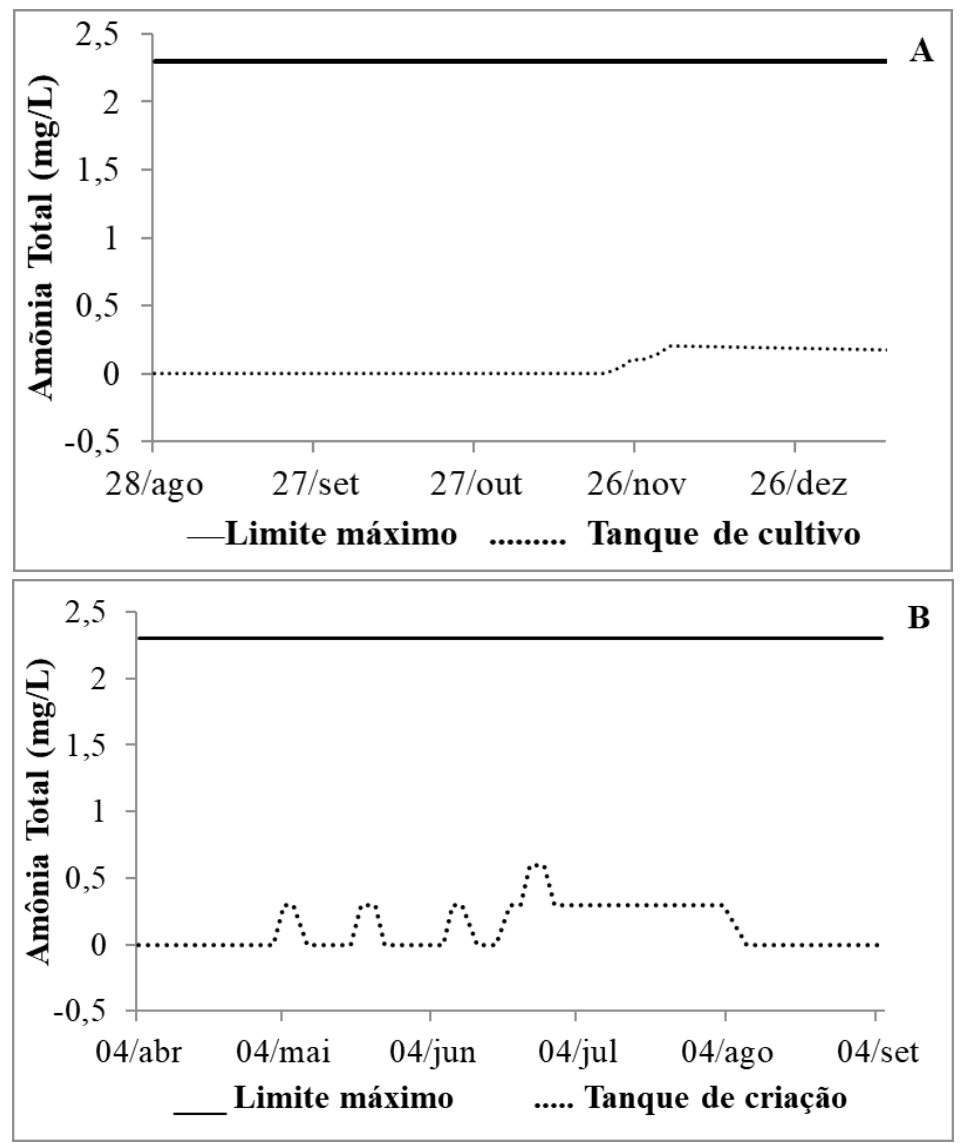

Fonte: Autoria própria.

Em relação à amônia não ionizada, as concentrações se mantiveram muito abaixo dos índices considerados tóxicos ( $0.2 \mathrm{mg} / \mathrm{L})$. Os valores máximos obtidos foram de $0.001 \mathrm{mg} / \mathrm{L}$ durante o primeiro manejo e $0.0028 \mathrm{mg} / \mathrm{L}$ durante o segundo manejo. A degradação da amônia tende a aumentar à medida que se eleva o pH da água (GSCHLÖBL et al., 1998).

$\mathrm{O}$ pH observado pode estar relacionado aos processos de formação do ácido carbônico, que acidifica o meio, e pelos processos de desnitrifi- 
cação, pois a cada grama de $\mathrm{NO}_{3}{ }^{-}$consumido, 3,0g de $\mathrm{CaCO}_{3}$ são formados e tornam a água mais alcalina, gerando um efeito tamponante (KADLEC; BURGOON; HENDERSON, 1997; ZIMMERMANN et al., 2001).

A concentração de nitrito na água também se manteve abaixo dos níveis considerados tóxicos, mesmo com a característica crescente no primeiro manejo (Figura 5A). No segundo manejo, observou-se que ocorreu a elevação dos níveis de nitrito nos dias mais frios do período, mas, com a elevação da temperatura, estes voltam à estabilidade em $0.1 \mathrm{mg} / \mathrm{L}$ (Figura 5B).

Figura 5 - Concentração média de nitrito no primeiro manejo (A) e no segundo manejo (B) de Oreochromis niloticus em sistema de recirculação associado a fitotratamento.

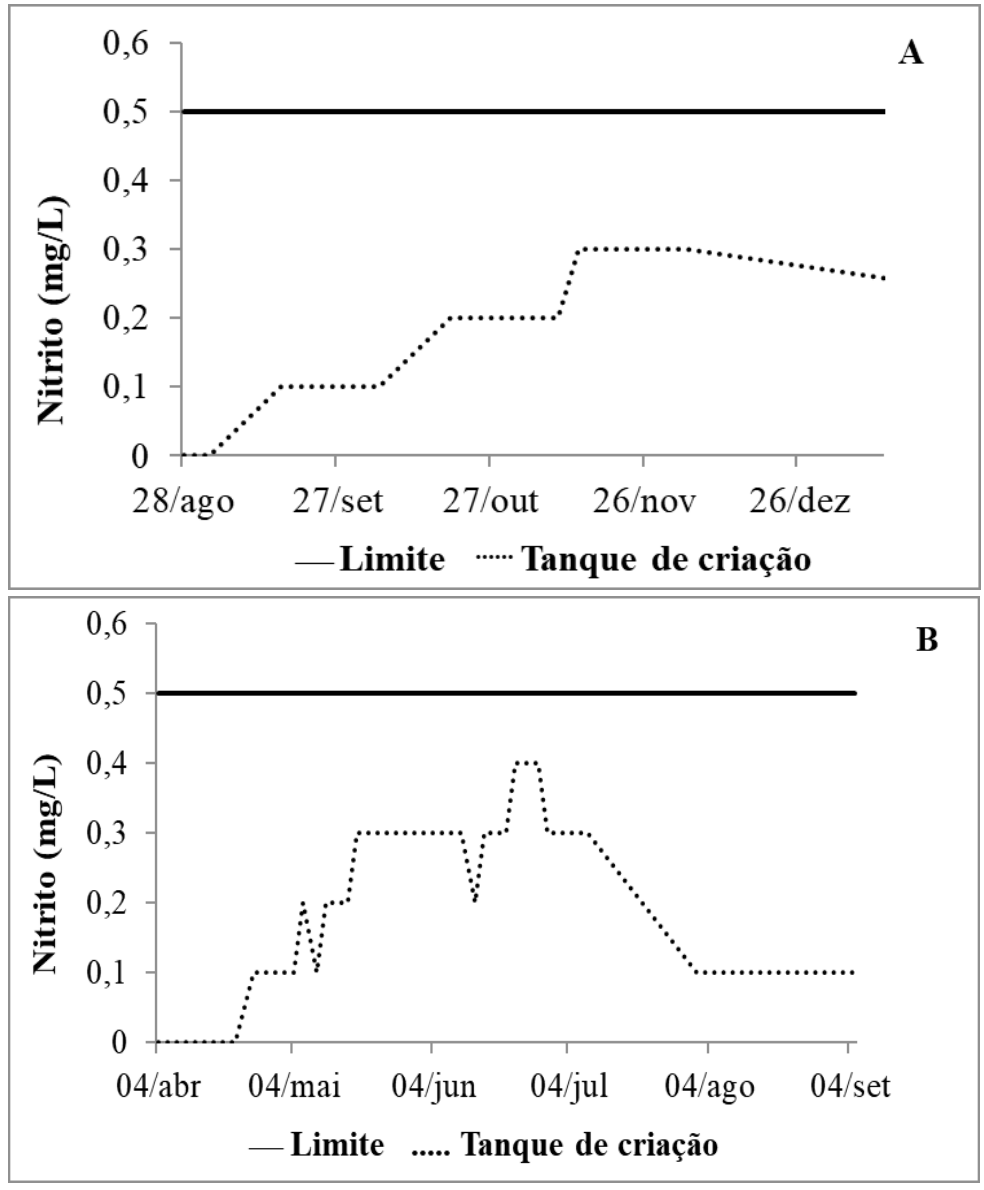

Fonte: Autoria própria. 
De maneira geral, atingiram-se as condições de qualidade da água necessárias à atividade aquícola durante os dois períodos de manejo. Os indicadores de produção (Tabela 2) refletem a produtividade do sistema. Embora as taxas de mortalidade de $32 \%$ no primeiro manejo e $20 \%$ no segundo manejo sejam altas, estas ocorreram nas primeiras semanas, indicando que podem estar associadas ao período de adaptação dos indivíduos ao habitat em que foram introduzidos. Nesse período de adaptação, cerca de $20 \%$ dos peixes morrem nos empreendimentos comerciais (OSTRENSKY; BOEGER, 1998), o que deixa o segundo manejo dentro da faixa esperada de perdas.

Tabela 2 - Indicadores de produção das duas etapas de manejo de Oreochromis niloticus em sistema de recirculação associado a fitotratamento.

\begin{tabular}{lcc}
\hline Indicador & Manejo 1 & Manejo 2 \\
\hline Indivíduos introduzidos & 50 & 45 \\
Indivíduos despescados & 32 & 36 \\
Peso médio inicial & 3,0 gramas & 6,0 gramas \\
Peso médio final & 50 gramas & 43.32 \\
Ganho de biomassa total & 1598 gramas & 1559,52 gramas \\
Ganho de biomassa individual & 47 gramas & 37,33 gramas \\
Conversão alimentar aparente 3,23 (Kg.ração/Kg.peixe) & 4,48 Kg.ração / Kg.peixe \\
Taxa de mortalidade & $32 \%$ & $20 \%$ \\
\hline
\end{tabular}

Fonte: Autoria própria.

A conversão alimentar aparente indicou que, para cada 3,23 kg de ração fornecida, se obteve $1 \mathrm{~kg}$ de peixe no primeiro manejo e no segundo, para se obter $1 \mathrm{~kg}$ de peixe, foram utilizados 4,48 kg de ração. Esses resultados estão muito superiores em relação aos obtidos em sistemas ideais de cultivo, nesses casos, a conversão alimentar aparente está entre 1 e 1,8 kg/kg (KUBITZA, 2006). O ganho de biomassa individual médio foi de 58,0 gramas em 105 dias e de 43,33 gramas em 149 dias. O baixo ganho de biomassa pode estar relacionado às baixas temperaturas durante os dois períodos de cultivo, o que também explica as baixas taxas de conversão alimentar.

A temperatura da água tem relação direta com a atividade metabólica dos peixes, se a temperatura varia, todo o metabolismo é afetado, em baixas temperaturas, os peixes deixam de comer e diminuem seu ritmo biológico (OSTRENSKY; BOEGER, 1998). Peixes cultivados em temperaturas entre $26 \mathrm{e}$ 
$28^{\circ} \mathrm{C}$ têm capacidade de crescimento de 99,5g em 75 dias (HEIN; PARIZOTTO; BRIANESE, 2004). Moura et al. (2007), em seu experimento, compararam ganho de biomassa individual médio de tilápias tailandesas cultivadas sob diferentes temperaturas $\left(20,24,28\right.$ e $\left.32^{\circ} \mathrm{C}\right)$. Os melhores resultados foram obtidos aos $32^{\circ} \mathrm{C}$ com os indivíduos atingindo o peso médio de 47,75 gramas em 55 dias. Enquanto que sob mesmo manejo alimentar, porém com a temperatura da água de $20^{\circ} \mathrm{C}$, obteve ganho de biomassa individual médio de 2,30 gramas no mesmo período de cultivo.

\section{CONCLUSÃO}

O sistema de recirculação de água associado ao fitotratamento mostrou-se viável às concentrações de amônia total, amônia não ionizada e nitrito, abaixo dos níveis considerados tóxico aos peixes.

Apesar de os indivíduos terem apresentado um baixo crescimento durante os dois períodos analisados, esse fato está associado às variações de alguns parâmetros físico-químicos em relação aos níveis ideais indicados para o cultivo da espécie, destacando o oxigênio dissolvido, que sofreu bruscas variações durante o primeiro manejo, e a temperatura, que se manteve muito abaixo dos níveis ideais durante a maior parte do tempo no segundo manejo. Estes parâmetros podem ter influenciado tanto no conforto, quanto no desenvolvimento desses animais.

\section{REFERÊNCIAS}

CASELLES-OSORIO, Aracelli; GARCIA, Joan. Impact of different feeding strategies and plant presence on the performance of shallow horizontal subsurface-flow constructed wetlands. Science of the Total Environent, Itália, v. 378, n. 3, p. 253-62, abr. 2007. DOI: https://doi.org/10.1016/j.scitotenv.2007.02.031

EATON, Andrew D.; CLESCERI, Lenore S.; RICE, Eduard W.; GREENBERG, Arnold E. (Ed.). Standard methodos for the examination of water and wastewater. 21. ed. Washington: American Public Health Association; American Water Works Association; Water Polution control Federation, 2005.

GONTIJO, Vicente de Paulo Macedo. Produção de tilápias do Nilo em fluxo contínuo de água: Manual para implantação de módulo de piscicultura. 2013. Disponível em: <http://www.epamig.br/index.php?option=com_docman\&task=doc_ download\&gid=3180>. 
GSCHLÖBL, T.; STEINMANN, C.; SCHLEYPEN, P.; MELZER, A. Constructed wetlands for effluent polishing of lagoons. Water Research, Grã-Bretanha, v. 32, n. 9, p. 2639-45, jan. 1998. DOI: 10.1016/S0043-1354(98)00047-5

HEIN, Gelson; PARIZOTTO, Maria L. V.; BRIANESE, Raul H. Tilápia: referência modular para o Oeste do Paraná- agricultor familiar, semi intensivo, tanques escavados, clima Cfa. Toledo: Ed. EMATER-PR, 2004. Disponível em: <http://www.iapar.br/ arquivos/File/zip_pdf/redereferencia/pp_modoeste.pdf>.

KADLEC, Robert H.; BURGOON, Peter S.; HENDERSON, Michael E. Integrated natural systems for treating potato processing wastewater. Water Science and Technology, England, v. 35, n. 5, p. 263-70, mar. 1997. DOI: https://doi.org/10.1016/ S0273-1223(97)00077-2

KUBITZA, Fernando. Tilápias: qualidade da água, sistemas de cultivo, planejamento da produção, manejo nutricional e alimentar e sanidade. Panorama da Aquicultura, São Paulo, v. 10, n. 59, p. 44-53, maio/jun. 2000. Disponível em: <http://www. acquaimagem.com.br/docs/Pan59_Kubitza.pdf>.

KUBITZA, Fernando. Sistemas de Recirculação: sistemas fechados com tratamento e reuso da água. Panorama da Aquicultura, Jundiaí-SP, v. 16, n. 95, p.15-22, maio/jun. 2006. Disponível em:<http://www.acquaimagem.com.br/docs/Pan95_Kubitza.pdf>.

MOURA, Guilherme S.; OLIVEIRA, Maria G. A.; LANNA, Eduarda T. A.; JÚNIOR, Alaor M.; MACIEL, Claudia M. R. R. Desempenho e atividade de amilase em tilápias-do-Nilo submetidas a diferentes temperaturas. Pesquisa Agropecuária Brasileira, Brasília, v. 42, n. 11, p. 1609-15, nov. 2007. DOI: 10.1590/S0100-204X2007001100013

OLGUÍN, Eugenia J.; SÁNCHEZ-GALVÁN, Gloria. Aquatic phytoremediation: novel insights in tropical and subtropical regions. Pure and Applied Chemistry, USA, v. 82, n. 1, p. 27-38, jan. 2010. DOI: https://doi.org/10.1351/PAC-CON-09-02-13

OSTRENSKY, Antonio; BOEGER, Walter. Piscicultura: fundamentos e técnicas de manejo. Guaíba, RS: Livraria e Editora Agropecuária, 1998. 34p. Disponível em: $<$ http://projetopacu.com.br/public/paginas/220-livro-pisciculturafundamentose-tecnicas-de-manejo.pdf>.

SIPAÚBA-TAVARES, Lúcia H.; MILLAN, Rodrigo N.; MILSTEIN, Ana. Limnology of an integrated cage-pond aquaculture farm. Acta Limnologica Brasiliensia, Rio Claro, SP, v. 28, e. 1, jun. 2016. DOI: http://dx.doi.org/10.1590/S2179-975X3014.

VYMAZAL, Jan; KRÖPFELOVÁ, Lenka. Removal of nitrogen in constructed wetlands with horizontal sub-surface flow: a review. Wetlands, Netherlands, v. 29, n. 4, p. 1114-24, dez. 2009.

ZIMMERMANN, Samuel; MOREIRA, Henrique; VARGAS, Laura; RIBEIRO Rita, Fundamentos da moderna aquicultura. Canoas, RS: Ed. ULBRA, 2001. 